\title{
Assortative Mating for Psychopathy Components and its Effects on the Relationship Quality in Intimate Partners
}

\author{
Igor Kardum, Jasna Hudek-Knezevic, Asmir Gračanin, Nermina Mehic \\ Department of Psychology, Faculty of Humanities and Social Sciences, \\ University of Rijeka, Croatia
}

\begin{abstract}
In three studies, we examined assortative mating for psychopathy components as well as its effects on the relationship quality in intimate partners. Compared to the original structure we confirmed three factors of psychopathy: criminal tendencies (CT), erratic lifestyle (ELS) and interpersonal manipulation (IM), while callous affect (CA) was not replicated. Hypotheses regarding positive versus negative assortment, initial assortment versus convergence, and active assortment versus social homogamy were tested. All hypotheses were examined using both variable-centered approach (VCA) and couple-centered approach (CCA). We found moderate positive assortment between intimate partners in psychopathy as a latent construct estimated by structural modelling. Furthermore, positive assortment for all three components of psychopathy was found either by using only VCA (CT), only CCA (IM) or both approaches (ELS). Additionally, initial assortment rather than convergence hypothesis and active assortment rather than social homogamy hypothesis was confirmed for all three psychopathy components, with a slight tendency towards divergence and social homogamy. We explored the effects of similarity in psychopathy components on the women and men' relationship quality by using profile similarity and polynomial regression analyses. Profile similarity in IM was significantly positively related to women's relationship quality, while the results of the polynomial regression analyses were more complex, and showed that only (dis)similarity in CT did not exert any effect on women and men's relationship quality. Greater disagreement between women and men's ELS was related with more sharp decrease of women's relationship quality, while men's relationship quality decreased at the higher levels of women and men's ELS. Greater disagreement between women and men's IM results in a lower women's relationship quality, while women and men's relationship quality was higher when women's IM was higher than men's.
\end{abstract}

Keywords: psychopathy components, assortative mating, initial assortment, active assortment, relationship quality

Igor Kardum, University of Rijeka, Faculty of Humanities and Social Sciences, Department of Psychology, Sveucilisna avenija 4, 51000 Rijeka, Croatia. E-mail: kardum@ffri.hr

Acknowledgements:

This research was supported by the University of Rijeka grant as a part of s research project "Personality, emotions and social processes as determinants of health outcomes (13.04.1.2.01)".

Special thanks to Marko Tončić and Irena Miletić for their help in graphical presentation. 


\section{Introduction}

Psychopathy as a personality disorder has had a long history of inquiry, as it is a topic of interest in different fields, such as psychiatry, psychology and law, to name a few. The main reason for this preoccupation are criminal behaviors and extreme violence, often related to psychopathy. However, the crucial elements in defining psychopathy are characteristics of personality rather than the above-mentioned behavioral manifestations (Glenn \& Raine, 2014). The most influential conceptualization of 'psychopathic traits' has been provided by Cleckley (1941). His constellation consists of 16 traits that describe individuals referred to as psychopaths, including their emotional (e.g., lack of remorse and shame), cognitive (e.g., poor judgment and failure to learn by experience), and interpersonal (e.g., unresponsiveness in general interpersonal relations) characteristics. Along with the development of self-report measures (e.g., Hare, 1985), the conceptualization of psychopathy as a non-pathological personality trait was introduced. This trait-like psychopathy is characterized by callous affect, low empathy and anxiety, interpersonal antagonism, antisocial tendencies, impulsiveness, and thrill-seeking (Jones \& Paulhus, 2010; Paulhus \& Williams, 2002). Today, there is a convincing body of empirical evidence indicating that psychopathy is a dimension with normal distribution in subclinical samples (Furnham, Richards, \& Paulhus, 2013; Glenn \& Raine, 2014), and is only quantitatively, but not qualitatively different from psychopathic personality disorder. This personality disorder may be considered as an extreme case of this trait, although the cutoff point between clinical and subclinical variant is somewhat artificial and arbitrary (Glenn \& Raine, 2014). Psychopathy as a personality dimension has gained even more popularity since Paulhus and Williams (2002) related it with subclinical forms of Narcissism and Machiavellianism and coined the term 'The Dark Triad' (DT). Apart from the conceptual similarity, empirical overlap between the three traits has been found, with correlation coefficients ranging from moderate to high (e.g., Lee \& Ashton, 2005; Paulhus \& Williams, 2002). Nevertheless, there is evidence that the DT traits represent distinct constructs (Furnham et al., 2013).

Regarding personality correlates from comprehensive taxonomies such as Fivefactor model, the results of a meta-analytic study (O'Boyle, Forsyth, Story, \& White, 2014) showed that psychopathy is moderately and negatively related to agreeableness and conscientiousness, while associations with the three remaining dimensions are positive but very small in size. In addition, relative importance analysis showed that the variance in psychopathy was primarily explained by agreeableness and conscientiousness. Similarly, in terms of HEXACO model, psychopathy was highly negatively correlated only with Honesty-Humility factor (Lee \& Ashton, 2005). Nevertheless, negative correlations with neuroticism and positive correlations with extraversion and openness have been occasionally found (e.g., Paulhus \& Williams, 2002). 
When it comes to intimate relationships, psychopathy seems quite incompatible with the idea of love and commitment. This intuitive claim was well supported by empirical evidence. Psychopathy was positively related to fast life history strategy (Jonason, Koenig, \& Tost, 2010a), and risky behavior (Figueredo et al., 2006), and negatively to protective life history factor which predicted decreased sexual coercion (Gladden, Sisco, \& Figueredo, 2008). Furthermore, psychopathy was found to be positively related to the frequency of lying in university undergraduates, both in mating and academic contexts (Baughman, Jonason, Lyons, \& Vernon, 2014), and promiscuity (Ali \& Chamorro-Premuzic, 2010). Additionally, individuals high in psychopathy seem to have double standards when it comes to adultery. Namely, although positively related to infidelity (Jones \& Weiser, 2014), psychopathy was also found to predict the revenge in hypothetical situations in which their partners cheated on them (Rasmussen \& Boon, 2014). Generally, psychopathy was positively related to the frequency of using mate retention tactics, especially those that refer to cost-inflicting behaviors (e.g., punishing mates' infidelity threat, violence against rivals) (Jonason, Li, \& Buss, 2010b; Shackelford, Goetz, \& Buss, 2005). Furthermore, all DT traits were positively correlated with the frequency and success in poaching mates from others as well as having been poached by others (Kardum, Hudek-Knezevic, Schmitt, \& Grundler, 2015). Individuals with higher levels of these traits also had their mates poached by others more frequently and successfully (Jonason et al., 2010b). To conclude, psychopathy was related to deceitful, exploitative and aggressive behaviors generally considered aversive and undesirable, and, therefore, are detrimental in the context of romantic relationships.

A systematic approach to psychopathy measurement started with the construction of Psychopathy Checklist Revised (PCL-R; Hare, 1991), a structured assessment instrument. Its initial version (PCL; Hare, 1980) was constructed on the basis of 16 criteria for psychopathy, set forth by Cleckley (1941). It was soon upgraded to a PCL-R, within which the two distinct but correlated factors were identified: 1. selfish, callous, and remorseless use of others, including interpersonal and affective items, and 2. chronically unstable and antisocial lifestyle, including items related to social deviance (Hare, 1991). The ability of PCL-R to predict antisocial and, in particular violent behavior made it a widely used instrument (for a review see Andrade, 2008).

Ten years later, on the basis of the literature review and a confirmatory factor analysis of the PCL-R, Cooke and Michie (2001) concluded that two-factor model could have not been sustained. One of their objections was that criminal or antisocial behavior aspect of psychopathy within PCL-R represented the outcome of an interaction between psychopathic tendencies, other personality traits and sociocultural factors, rather than the psychopathic trait itself. Consequently, they developed a three-factor model consisting of 1. Interpersonal (arrogant and deceitful interpersonal style) and 2. Affective (deficient affective experience) factors that together correspond to the earlier selfish, callous, and remorseless use of others 
factor, as well as 3. Impulsive and irresponsible behavioral style factor that only partly corresponded to chronically unstable and antisocial lifestyle factor identified by Hare (1991), because of the exclusion of the items related to violent and antisocial behavior. This three-factor structure was reliable and replicated in some other studies (e.g. Pérez, Herrero, Velasco, \& Rodriguez-Díaz, 2015). However, the absence of antisocial behavioral items resulted in much weaker prediction of violent behavior and, therefore, the procedure of excluding and including items into PCL scale by Cooke and Michie (2001) was questioned by some researchers (e.g. Hare, 2003; Neumann, Vitacco, Hare, \& Wupperman, 2005; Vitacco, Neumann, \& Jackson, 2005), which resulted in further exploration of the factor structure of psychopathy. Hare and Neuman (2006) tested a 4-factor model that included both the three-factors observed by Cooke and Michie (2001) and the additional antisocial behavior factor. The new structure consisting of Interpersonal, Affective, Lifestyle, and Antisocial facets, was supported in the initial as well as in several subsequent studies conducted by using PCL scales (e.g. Neuman \& Hare, 2008) and other psychopathy measures as well (Mahmut, Menictas, Stevenson, \& Homewood, 2011). Namely, in addition to the structured assessment instruments such as PCL-R, which require training and are time consuming, the field greatly benefited from the development of self-report instruments. While there is no consensus about the conceptual validity of some of these instruments (e.g. Psychopathic Personality Inventory revised; PPI-R; Lilienfeld $\&$ Widows, 2005), early development of Self-Report Psychopathy scale (SRP; Hare, 1985), and subsequent revised versions (e.g. SRP-II; Hare, Harpur, \& Hemphill, 1989) provided a useful tool for the assessment of psychopathy in non-clinical community samples.

With the aim of designing a self-report scale that would adequately capture the four factors identified in the studies using PCL scales, Williams, Paulhus, and Hare (2007) upgraded the SRP-II scale by removing the items relating to anxiety and by adding those relating to antisocial behavior. The resulting SRP-E scale (or SRP-III as later referred to by Neumann, Schmitt, Carter, Embley, \& Hare, 2012) was proven to adequately tap the four factors observed in numerous studies using PCL scales. The new factors were labeled: 1. Interpersonal Manipulation, including behaviors such as pathological lying and manipulating; 2. Criminal Tendencies, consisting primarily of newly added antisocial behavior items; 3. Erratic Lifestyle, based on the items reflecting undependability, recklessness, and impulsivity; and 4. Callous Affect, reflecting deficiencies in remorse, guilt and empathy. The factors that formed the oblique four-factor structure were positively inter-correlated, suggesting a common underlying factor of psychopathy, which was also proven reliable. The model consisting of four specific SRP-III factors and the higher-order factor of psychopathy showed better fit indices than the model based on the earlier three-factor SRP-II structure. In addition, the higher order factor and the four specific factors showed convergent and divergent validity in relation to theoretically relevant personality, psychopathology, and misconduct behavioral criteria (Williams et al., 2007). Finally, a strong support for the four-factor structure was recently found in a 
large international study on a sample of more than fifty thousand participants in which a 19-items SRP-III scale was used (Neumann et al., 2012).

Assortative mating is defined as nonrandom coupling of individuals that could be positive and negative. Positive assortment is based on trait similarity, while negative on trait dissimilarity (Buss, 1984). There is a wide range of traits for which romantic partners positively assort such as anthropometric characteristics, achievement and ability measures and many sociological and demographic indices (Thiessen \& Gregg, 1980). Predominantly positive assortative mating has also been found for numerous personality traits, with mostly low to moderate correlations between partners (McCrae et al., 2008; Watson et al., 2004). Partners also positively assort for a wide range of undesirable and antisocial characteristics such as bipolar disorder and major depression (Mathews \& Reus, 2001), substance use disorders (Low, Cui, \& Merikangas, 2007) and antisocial behaviors (Krueger, Moffit, Caspi, Bleske, \& Silva, 1998), as well as personality traits such as psychoticism (DubuisStadelmann, Fenton, Ferrero, \& Preisig, 2001). Assortment for other socially undesirable personality traits such as psychopathy has very rarely been explored. Among the few studies on this topic, moderate positive assortment was found for psychopathy on the small sample of dating couples (Smith et al., 2014), as well as on the bigger sample of dating couples by using both VCA and CCA (Kardum, HudekKnezevic, Schmitt, \& Covic, 2016). Generally, this very limited evidence suggests that people are prone to mate with partners similar to themselves in psychopathy.

As was mentioned before, contemporary conceptualizations of psychopathy suggest that it is a multidimensional trait, and, therefore, it could be questioned whether similar degree of assortment found for overall psychopathy also exists on the level of its components. For example, when examining the assortment for the five factor personality traits facets, McCrae et al. (2008) found that N3: Depression showed relatively consistent low positive assortment across several cultures, while N1: Anxiety did not. Differences in assortment between facets were especially pronounced for Openness domain showing moderate positive assortment for $\mathrm{O}$ 2: Aesthetics and O6: Values, and no assortment at all for O1: Fantasy. As far as we know, Savard, Sabourin, and Lussier (2011) conducted the only study that explored assortative mating for different psychopathy components. They found moderate positive assortment for global and primary psychopathy and low positive assortment for secondary psychopathy on the sample of young married and cohabitating couples.

There are several reasons why it is important to explore the assortment for personality traits as well as their components. One reason is that (dis)similarity in personality traits may have different effects on relationship outcomes. For example, evidence suggests that positive assortment found for personality traits as well as other characteristics such as intelligence, attitudes and interests is often positively related to satisfaction and quality of a relationship (Luo \& Klohnen, 2005; Schmitt, 2002). Therefore, exploring the assortment on the lower level of personality traits enable us to describe more precisely the nature of the relations between the similarity in a 
personality trait and various relationship outcomes. Furthermore, exploring the assortment for specific components of personality traits may contribute to the better understanding of the impact of homogeneous or heterogeneous family environment on child rearing. Additionally, assessment of the degree of assortment is important for the accurate estimation of heritability (Plomin, DeFries, Knopik, \& Neiderhiser, 2013).

The main aim of this study was to examine the degree of assortment for different components of psychopathy and its effects on the relationship quality on the samples of dating, cohabitating and married couples. Additionally, we examined whether the assortment for psychopathy components may be attributed to the initial assortment (i.e., couples are already similar in psychopathy components at the beginning of their relationship) or convergence (i.e., couples became more similar over time). We also tested active assortment hypothesis (i.e., a preference for mating with a partner who is similar on a particular psychopathy component) vs. social homogamy (i.e., mating partner with similar social background that may be responsible for similarity in psychopathy components).

Assortative mating was assessed by using two methodological approaches, variable-centered approach and couple-centered approach (Luo \& Klohnen, 2005). Variable-centered approach is based on a correlation between partners' scores on the same characteristic across all couples in a sample, while couple-centered approach shows how similar each pair is in terms of their profiles of responses across a number of items.

According to the results of the previous studies, we hypothesized low to modest positive assortment for psychopathy components. Because psychopathy is a multidimensional trait, we should not assume that they have the same degree of assortment. Previous evidence show that assortment for personality traits is mainly not due to convergence, nor to social homogamy (Watson et al., 2004), and, therefore, stronger support for initial and active assortment for psychopathy components was expected. Additionally, we expected the confirmation of these hypotheses using both variable- and couple-centered approach. Regarding the effects of similarity, we hypothesized that partners' similarity in psychopathy components will generally exert positive, while dissimilarity will have negative effects on the relationship quality. 


\section{Study 1}

The aim of Study 1 was to examine the factor structure of Self-Report Psychopathy Scale (SRP-III-E; Williams et al., 2007) in Croatian language.

\section{Method}

\section{Participants and Procedure}

The study was conducted on the sample of 1456 participants (777 women and 679 men) from several towns in Croatia, recruited by opportunity sampling method. The age of participants ranged from 18 to 87 years $(M=34.89 ; S D=17.10)$. Questionnaires were administered by well-instructed psychology students in the homes of the participants. Participation was voluntary and anonymous with no incentives offered. All participants reviewed a letter of information, signed informed consent and then completed the questionnaires.

\section{Measures}

Psychopathy was assessed with the 31-item version of the Self-Report Psychopathy Scale (SRP-III-E; Williams et al., 2007) that has been translated into Croatian (Kardum et al., 2015). Originally modeled after the Psychopathy ChecklistRevised (PCL-R; Hare, 2003), SRP-III-E is an early version of the SRP that has been found to be highly correlated with the most recent version of SRP (Paulhus, Neumann, \& Hare, in press). An oblique four-factor structure of this questionnaire was found: CT (e.g. "I have attacked someone with the idea of seriously hurting him or her"), ELS (e.g. "I enjoy driving at high speed"), IM (e.g. "It is sometimes fun to see how far you can push someone before they catch on"), and CA (e.g. "I am the most important person in this world and nobody else matters") (Williams, Nathanson, \& Paulhus, 2003; Williams et al., 2007). SRP-III items describe less extreme behaviors than PCL-R items and are, therefore, more appropriate for subclinical samples. The validity and psychometric properties of the original SRPIII version have been supported in numerous studies (e.g., Paulhus \& Williams, 2002; Williams et al., 2003). Responses are scored on a scale from 1 (strongly disagree) to 5 (strongly agree).

\section{Results}

First, exploratory factor analysis on all 31 SRP items was performed. Number of factors to be retained was guided by two decision rules: Kaiser's criterion (eigen values above 1) and Horn's parallel analysis, and they suggested that three to five 
factors should be retained. However, five CA items were problematic because they did not load clearly on one factor and because of generally low factor loadings. This is probably the consequence of very low Cronbach alpha reliability coefficient obtained for that factor (.21), and, therefore, CA items were omitted from further analyses. Exploratory factor analysis performed without these items suggested that three factors should be retained, with minimal differences from the original structure.

A confirmatory factor analysis (CFA) on the variance-covariance matrix between 26 items, using LISREL 8.30 (Jöreskog \& Sörbom, 1999) was additionally performed. As a reference point, we first tested a unidimensional measurement model in which all SRP items are hypothesized to load on a single factor. In the second model, three-factor structure of the SRP (CT, ELS and IM) was tested. Three latent factors were allowed to correlate freely. Generally, normed fit index (NFI), comparative fit index (CFI) and goodness of fit index (GFI) $\geq .90$, root mean square error of approximation (RMSEA) $\leq .08$ and root mean square residual $(\mathrm{RMR}) \leq .10$ indicate good model fit (Hu \& Bentler, 1998; Kline, 1998; Schermelleh-Engel, Moosbrugger, \& Müller, 2003). As it is well known, chi-square statistic is conservative and sensible to sample size, and therefore, in larger samples it is rarely non-significant. Several authors suggest that $\chi^{2} / d f$ can also be calculated (normed chisquare; NC), and values of less than 3 are considered favorable (Kline, 1998). Goodness-of-fit indices for both models are presented in Table 1.

Table 1. Goodness-of-Fit Indices for One- and Three-Factor Models

\begin{tabular}{lcc}
\hline Goodness-of-fit indices & One-factor model & Three-factor model \\
\hline & $\begin{array}{c}\chi^{2}=4102.46 \\
d f=299\end{array}$ & $\chi^{2}=2510.15$ \\
Chi-square & $p<.001$ & $d f=296$ \\
& 13.72 & $p<.001$ \\
\hline Normed Chi-square (NC) & .65 & 8.48 \\
Normed Fit Index (NFI) & .67 & .75 \\
Comparative Fit Index (CFI) & .82 & .78 \\
Goodness of Fit Index (GFI) & .09 & .88 \\
Root Mean Square Error of & .07 & .07 \\
Approximation (RMSEA) & & .08 \\
Root Mean Square Residual (RMR) & & \\
\hline
\end{tabular}

Although both models do not have satisfactory goodness-of-fit indices, the results show that three-factor was better than one-factor model, which was also confirmed by the quantitative comparison of the two models $\left(\Delta \chi^{2}=1592,31 ; d f=3\right.$; $p<.001)$. As it is known, $\Delta \chi^{2}$ index of difference in fit has been criticized because of its sensitivity to the sample size. It has been suggested that $\triangle \mathrm{CFI}$ is not prone to this problem and that a $\triangle$ CFI value higher than .01 indicates significant drop in fit (Hu \& Bentler, 1998). Thus, the $\Delta$ CFI obtained was .11, also indicating that three-factor model fits better to the data than one-factor. Cronbach alpha internal reliability coefficients were .85 for total SRP, .74 for CT, .78 for ELS and .60 for IM. CT was 
significantly correlated with ELS $(.51 ; p<.001)$ and IM $(.41 ; p<.001)$, while ELS was significantly correlated with IM $(.50 ; p<.001)$. All subscales and total SRP score were negatively correlated with age: CT -.34 ( $p<.001)$, ELS -.43 ( $p<.001)$, IM -.24 $(p<.001)$ and total SRP score $-.43(p<.001)$. Men were significantly higher than women on CT $(t=11.04 ; p<.001 ; d=0.59), \operatorname{ELS}(t=6.14 ; p<.001 ; d=0.32), \operatorname{IM}(t=8.12$; $p<.001 ; d=0.43)$, and on total SRP score $(t=10.38 ; p<.001 ; d=0.55)$.

\section{Study 2}

The aim of Study 2 was to explore the assortative mating in psychopathy components by using VCA and CCA. In addition, two hypotheses, initial assortment vs. convergence and active assortment vs. homogamy were tested.

\section{Method}

\section{Participants and Procedure}

A convenience sample of 288 heterosexual married, cohabiting and dating couples was recruited using snowball method. Their relationship lengths ranged from 0.5 to 50 years $(M=12.06 ; S D=11.24)$, and age from 18 to 73 years $(M=34.91$; $S D=12.70)$. Majority of men (50\%) and women (35.42\%) had high school education, and $51.73 \%$ of men and $47.22 \%$ of women were employed. All participants first provided informed consent, and then completed the questionnaires. Two psychology students administered the questionnaires to each couple in their homes or at the university premises. To ensure independent responding, partners were asked to sit apart from each other while completing the questionnaires.

\section{Measure}

In accord with the results of the Study 1, psychopathy was assessed with the 26item version of the Self-Report Psychopathy Scale (SRP-III-E; Williams et al., 2007) which includes three subscales: CT, ELS and IM. Cronbach alpha coefficients of internal reliability obtained on this sample were .76 for CT, .75 for ELS and .53 for IM. 


\section{Results}

First, we present the results of VCA analyses. Descriptive statistics for psychopathy components, age, and years of education for women and men are presented in Table 2.

Table 2. Descriptive Statistics for Psychopathy Components, Age, and Years of Education for Women and Men

\begin{tabular}{lrrrrrr}
\hline \multirow{2}{*}{ Variables } & \multicolumn{2}{c}{ Women } & \multicolumn{2}{c}{ Men } & \multirow{2}{*}{$t$} & \multirow{2}{*}{$d$} \\
\cline { 2 - 5 } & \multicolumn{1}{c}{$M$} & $S D$ & $M$ & \multicolumn{1}{c}{$S D$} & & \\
\hline CT & 16.60 & 4.57 & 19.33 & 5.82 & $7.22^{*}$ & 0.52 \\
ELS & 19.51 & 5.03 & 22.45 & 5.31 & $8.04^{*}$ & 0.57 \\
IM & 14.42 & 3.22 & 16.21 & 3.72 & $6.45^{*}$ & 0.51 \\
Age & 33.78 & 12.30 & 35.94 & 12.99 & $11.62^{*}$ & 0.17 \\
Education (years) & 14.06 & 2.10 & 13.54 & 2.05 & $4.24^{*}$ & 0.25 \\
\hline
\end{tabular}

Note. $M=$ mean; $S D=$ standard deviation; $t=t$-test; $d=$ Cohen's $d$.; CT = Criminal tendencies; ELS = Erratic lifestyle; IM = Interpersonal manipulation. ${ }^{*} p<.001$.

Men scored significantly higher on all psychopathy components; they were older than women were and somewhat less educated. The relationship between psychopathy components and their correlations with age, education, and relationship length in women and men are presented in Table 3.

Table 3. Relationship between Psychopathy Components and their Correlations with Age, Years of Education and Relationship Length in Women and Men

\begin{tabular}{lccllll}
\hline \multirow{2}{*}{ Variables } & \multicolumn{3}{c}{ Women } & \multicolumn{3}{c}{ Men } \\
\cline { 2 - 7 } & CT & ELS & IM & CT & ELS & IM \\
\hline CT & & $.43^{* * *}$ & $.34^{* * *}$ & & $.58^{* * *}$ & $.34^{* * *}$ \\
ELS & & $.36^{* * *}$ & & & $.45^{* * *}$ \\
Age & $-.18^{* *}$ & $-.30^{* * *}$ & $-.13^{*}$ & $-.24^{* * *}$ & $-.33^{* * *}$ & $-.15^{*}$ \\
Education (years) & -.04 & .07 & -.02 & -.07 & .02 & -.02 \\
Length of relation & $-.16^{* *}$ & $-.26^{* * *}$ & -.08 & $-.26^{* * *}$ & $-.35^{* * *}$ & $-.15^{*}$ \\
\hline
\end{tabular}

Note . $\mathrm{CT}=$ Criminal tendencies; ELS = Erratic lifestyle; $\mathrm{IM}=$ Interpersonal manipulation. ${ }^{*} p<.05 ;{ }^{* *} p<.01 ;{ }^{* * *} p<.001$.

Psychopathy components were positively and mainly moderately related in both samples. Except the correlation between relationship length and IM on women, all other correlations of age and relationship length with psychopathy components were significantly negative in both samples, while years of education were not significantly related to any of the psychopathy components. 
Similar to previous research, very high positive assortment was found for age ( $r=.97 ; p<.001)$, and to a lesser degree for education $(r=.49 ; p<.01)$. In order to assess assortative mating, the correlations between men and women's psychopathy components were computed. The initial assortment versus convergence hypothesis was tested by partialling out the effects of the duration of the relationship because if couple similarity is mostly due to convergence, then partners who have been together longer should be more similar to each other. This hypothesis was additionally tested by log-transforming the duration of the relationship, and thus we gave more weight to the shorter relationship duration, assuming that several months in a short relationship matter much more in terms of time than the same amount of time in a long relationship. We tested the active assortment versus social homogamy hypothesis by partialling out the effects of five variables: women's age and education, men's education and interaction terms of women and men's age and education computed from centered values. Men's age was excluded from this analysis because of its high correlation with women's age. Age and education are two key sociodemographic variables that could be important sources of social homogamy (Watson et al., 2004). If controlling for these variables substantially reduces the size of cross-partner correlations, it may suggest that similarity is primarily due to social homogamy rather than active assortment. The correlations and partial correlations are presented in Table 4.

Table 4. Correlations and Partial Correlations between Women and Men on Psychopathy Components

\begin{tabular}{|c|c|c|c|}
\hline \multirow{2}{*}{ Men } & \multicolumn{3}{|c|}{ Women } \\
\hline & CT & ELS & IM \\
\hline \multirow{4}{*}{ CT } & $.26^{* * *}$ & $26^{* * * *}$ & .04 \\
\hline & $.23^{* * * *}$ & $.21^{* * *}$ & .02 \\
\hline & $.23^{* * * *}$ & $.20^{* * *}$ & .01 \\
\hline & $.19^{* *}$ & $.19^{* *}$ & .02 \\
\hline \multirow{4}{*}{ ELS } & $.22^{* * * *}$ & $29^{* * * *}$ & $.15^{*}$ \\
\hline & $.18^{* *}$ & $.22^{* * * *}$ & $.13^{*}$ \\
\hline & $.18^{* *}$ & $.19^{* *}$ & $.12^{*}$ \\
\hline & $.16^{* *}$ & $.19^{* * *}$ & $.12^{*}$ \\
\hline \multirow{4}{*}{ IM } & $.22^{* * * *}$ & .10 & .09 \\
\hline & $.20^{* * * *}$ & .06 & .08 \\
\hline & $.19^{* *}$ & .05 & .07 \\
\hline & $.19^{* *}$ & .06 & .07 \\
\hline
\end{tabular}

Note. CT = Criminal tendencies; ELS = Erratic lifestyle; IM = Interpersonal manipulation; first row - correlations between women and men; second row - partial correlations (controlling for relationship length); third row - partial correlations (controlling for log relationship length); fourth row - partial correlations (controlling for age and years of education for each partner as well as their interactions).

${ }^{*} p<.05 ;{ }^{* *} p<.01 ;{ }^{* * *} p<.001$. 
The results show significant positive assortment for CT and ELS, and no assortment for IM. Significant non-diagonal correlations were also found. The sizes of these correlations were similar to those indicating positive assortment for psychopathy components, suggesting that couples did not match only according to the similarity in the same but also according to the similarity in the different psychopathy components.

Partialling out the length of the relationship yielded non-significantly different cross-partner correlations, which is in accord with the initial assortment hypothesis. The control of five variables related to age and education also resulted in nonsignificant changes in the correlations between men and women, which is in accord with active assortment hypothesis.

The degree of assortment was also assessed by computing the relationship between two latent constructs, men and women's psychopathy, by using structural equation modeling (LISREL 8.30; Jöreskog \& Sörbom, 1999). Two models were tested. First hypothesized that men and women's latent psychopathy constructs are orthogonal (i.e., no assortative mating) and the second that they are obliquely related (i.e., assortative mating). Goodness-of-fit indices for the orthogonal model $\left(\chi^{2}(9)=47.82 ; p<.001 ; \chi^{2} / d f=5.31\right.$, normed fit index $(\mathrm{NFI})=.79$, comparative fit index $(\mathrm{CFI})=.87$, goodness of fit index $(\mathrm{GFI})=.95$, root mean square error of approximation $($ RMSEA $)=.12$, root mean residual $(\mathrm{RMR})=.13$ ) show its relatively poor adjustment to the data, while the indices for the oblique model, $\chi^{2}(8)=17.83, p=.02, \chi^{2} / d f=2.23$, $\mathrm{NFI}=.95, \mathrm{CFI}=.97, \mathrm{GFI}=.98$, RMSEA $=.06, \mathrm{RMR}=.04$, show its good fit to the data. Quantitative comparison also shows that the oblique model is better than orthogonal $\left(\Delta \chi^{2}(1)=29.99 ; p<.001 ; \Delta \mathrm{CFI}=.10\right)$. The correlation obtained between women and men's psychopathy is moderate (.44). The oblique model is presented in Figure 1.

In order to examine assortative mating by CCA, intra-pair correlations were computed across all items on each psychopathy component. Various factors (e.g. shared cultural values, social desirability, response bias) may affect individuals' tendency to mate with similar partners, and, therefore, the evaluation of the actual degree of couples' similarity is needed (Luo \& Klohnen, 2005). One way to evaluate similarities between partners is to compare intra-pair correlations on each psychopathy component obtained on real couples with those obtained on randomly paired couples. In this study profile similarity on 300 randomly paired couples was computed and then compared to those obtained on real couples. Table 5 presents descriptive statistics for real and randomly paired couples and the results of $t$-tests. 


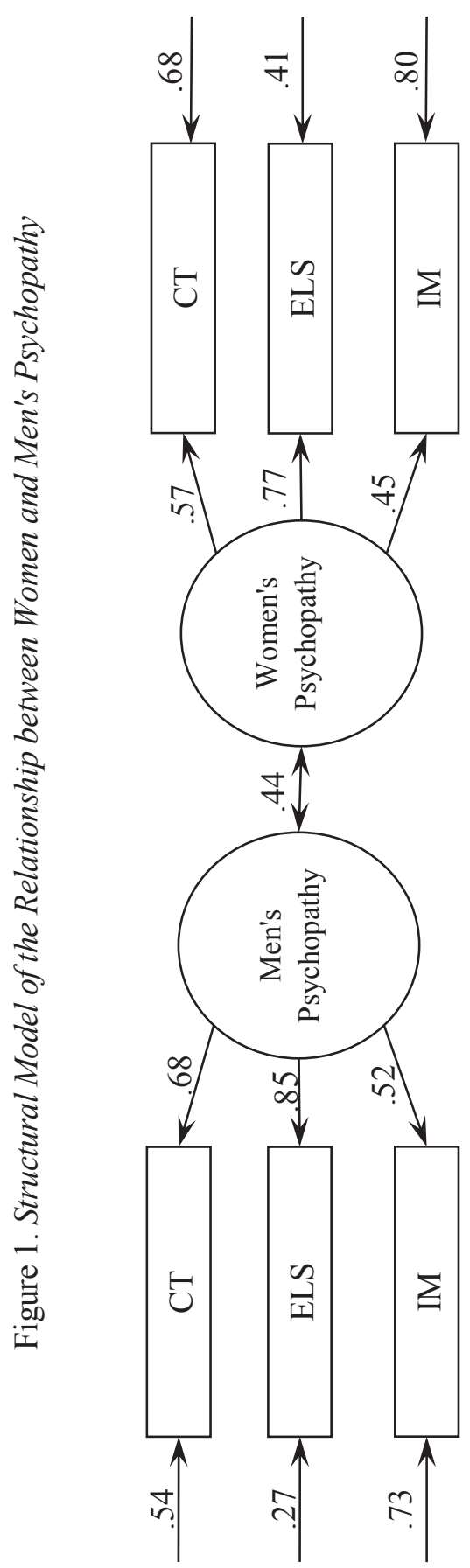


Table 5. Descriptive Statistics for Intra-pair Correlations in Real and Randomly Generated Couples and the Results of t-tests

\begin{tabular}{llllll}
\hline Variable & Couples & $M$ & $S D$ & $t$ & $d$ \\
\hline \multirow{2}{*}{ CT } & real & .60 & .34 & \multirow{2}{*}{1.64} & \multirow{2}{*}{0.15} \\
& random & .55 & .33 & & \\
\hline \multirow{2}{*}{ ELS } & real & .35 & .37 & \multirow{2}{*}{$4.08^{* * *}$} & \multirow{2}{*}{0.33} \\
& random & .23 & .36 & & \multirow{2}{*}{0.37} \\
\multirow{2}{*}{ IM } & real & .37 & .39 & $4.35^{* * * *}$ & 0.37 \\
& random & .22 & .41 & & \\
\hline
\end{tabular}

Note. $t=t$-value; $d=$ Cohen's $d$; CT = Criminal tendencies; ELS = Erratic lifestyle; IM = Interpersonal manipulation.

${ }^{*} p<.001$.

The results show significantly higher mean intra-pair similarity in the real compared to the randomly paired couples for ELS and IM, but not for CT. In order to examine how many of the real and randomly paired couples mated assortatively, we additionally analyzed the percent of significant correlations on each psychopathy component. Positive assortment for CT was found in $85.5 \%$ of the real and $86.9 \%$ of the randomly paired couples $\left(\chi^{2}(2)=0.70 ; p=.71\right)$, for ELS in $69.4 \%$ of the real and $56.3 \%$ of the randomly paired couples $\left(\chi^{2}(2)=10.76 ; p<.01\right)$, and for IM in $67.1 \%$ of the real and $57.9 \%$ of the randomly paired couples $\left(\chi^{2}(2)=8.16 ; p=.02\right)$. These analyses additionally confirmed that when CCA was used positive assortment was found for ELS and IM, and no assortment for CT.

Intra-pair similarity in CT was negatively correlated with relationship length ($.13 ; p<.05)$ and $\log$ transformed relationship length $(-.14 ; p<.05)$, while intra-pair similarity in IM was negatively correlated with log transformed relationship length $(-.13 ; p<.05)$. These results suggest a slight tendency towards divergence between partners in CT and IM. We also tested active assortment versus social homogamy hypothesis by computing correlations of similarity in psychopathy components with women's age and education, men's education as well as with interaction terms of women and men's age and education. Significant negative correlation was obtained between women's age $(-.14 ; p<.05)$ and profile similarity in CT, indicating that profile similarity in this component of psychopathy was somewhat higher in couples with younger women. Profile similarity in ELS was positively correlated with men's education $(.13 ; p<.05)$, suggesting that profile similarity in ELS was somewhat higher in couples in which men were more highly educated. Although these results are in line with social homogamy hypothesis, generally the results obtained provide more support for the active assortment hypothesis. 


\section{Study 3}

The aim of Study 3 was to examine the effects of similarity in psychopathy components on the relationship quality of women and men by using profile similarity and polynomial regression analyses.

\section{Method}

\section{Participants and Procedure}

A convenience sample of 100 young urban heterosexual dating couples was recruited using snowball method. These couples were also a part of the sample used in the Study 2. Their relationship lengths ranged from 6 months to 11 years $(M=3.50$ years; $S D=3.76$ years), with $23 \%$ of couples living together. Participants' age ranged from 18 to 31 years ( $M=24.57$ years; $S D=3.16$ for men; $M=23.20$ years; $S D=2.57$ for women). The majority of men (55\%) and women (67\%) had university degree. Men were significantly older $(t=3.36 ; p<.001 ; d=0.47)$, and had fewer years of education $(t=2.43 ; p<.05 ; d=0.34)$ than women. Only $13 \%$ of men and $11 \%$ of women were employed, $43 \%$ of men and $66 \%$ of women were unemployed, and $44 \%$ of men and $23 \%$ of women were university students. All participants first provided informed consent, and then completed the questionnaires. Assessment was carried out at the university premises, under the supervision of two psychology students. To ensure independent responding, partners were asked to sit apart from each other while completing the questionnaires.

\section{Measures}

Psychopathy was assessed with the 26-item version of the SRP-III-E (Williams et al., 2007) which includes three subscales: CT, ELS and IM.

Relationship quality was measured by three questionnaires. Perceived Relationship Quality Components questionnaire (Fletcher, Simpson, \& Thomas, 2000) consists of six items that measure one aspect of the relationship (love, passion, commitment, trust, satisfaction, and intimacy). Satisfaction with different attributes of a current partner (e.g. financial resources, physical attractiveness, ability to provide emotional support, reliability/trustworthiness) was measured by 11-item Satisfaction Index (Simpson, 1987), while 9-item Marital Stability Scale (Ćubela Adorić \& Vugdelija, 2010) adapted for dating couples, was used to measure relationship stability and sustainability (e.g. "We have what it takes to maintain our relationship"). There were no significant gender differences on these three measures. Because they were highly correlated $(r=.75-.80)$, principle-axis factor analysis was performed, and it yielded one factor. All three measures loaded well (>.84) on a single factor that accounted for $76.92 \%$ of the variance $($ Eigen $=2.54)$, and, therefore, 
we collapsed them into a single overall relationship quality index using factor scores as weights.

\section{Results}

As a measure of couple's (dis)similarity we also used profile similarity by computing intra-pair correlations across all items for each psychopathy component. Descriptive statistics, Cronbach alpha coefficients, and correlations between all measures used in this study are presented in Table 6.

Table 6. Descriptive Statistics and Correlations for all Variables

\begin{tabular}{|c|c|c|c|c|c|c|c|c|c|c|c|}
\hline Variables & 1. & 2. & 3. & 4. & 5. & 6. & 7. & 8. & 9. & 10. & 11. \\
\hline 1. $\mathrm{CT}-\mathrm{W}$ & - & $.44^{* * *}$ & $.41^{* * * *}$ & $.27^{* *}$ & $.27^{* *}$ & $.32^{* * * *}$ & .10 & -.18 & -.02 & -.12 & -.06 \\
\hline 2. $E L S-W$ & & - & $.44^{* * *}$ & .10 & .13 & -.02 & .03 & -.00 & -.05 & $-.21^{*}$ & $-.22^{*}$ \\
\hline 3. IM - W & & & - & .04 & .14 & $.21^{*}$ & -.09 & .03 & .03 & .06 & .06 \\
\hline 4. CT $-\mathrm{M}$ & & & & - & $.56^{* * * *}$ & $.41^{* * * *}$ & -.09 & -.16 & -.12 & $-.23^{*}$ & $-.39^{* * * *}$ \\
\hline 5. ELS - M & & & & & - & $.55^{* * *}$ & .04 & .00 & .06 & $-.25^{*}$ & $-.31^{* *}$ \\
\hline 6. IM-M & & & & & & - & .14 & -.08 & .05 & $-.25^{*}$ & $-.37^{* * * *}$ \\
\hline 7. $\mathrm{CT}-\mathrm{PS}$ & & & & & & & - & .06 & $.29^{* *}$ & -.02 & -.06 \\
\hline 8. ELS - PS & & & & & & & & - & .06 & .02 & .01 \\
\hline 9. IM-PS & & & & & & & & & - & $.23^{*}$ & .16 \\
\hline 10. ORQ - W & & & & & & & & & & - & $.68^{* * *}$ \\
\hline 11. ORQ - M & & & & & & & & & & & - \\
\hline $\begin{array}{l}\text { Cronbach's } \\
\text { alpha } \\
\end{array}$ & .64 & .73 & .61 & .79 & .74 & .65 & - & - & - & .85 & .87 \\
\hline Mean & 17.41 & 21.93 & 14.81 & 20.82 & 24.92 & 17.04 & .63 & .40 & .43 & -0.05 & 0.05 \\
\hline Std. deviation & 4.00 & 5.05 & 3.58 & 6.14 & 5.26 & 4.01 & .32 & .37 & .40 & 0.96 & 0.95 \\
\hline
\end{tabular}

Note. ORQ - Overall Relationship Quality; $\mathrm{W}$ - women; $\mathrm{M}$ - men; PS - profile similarity; CT = Criminal tendencies; ELS= Erratic lifestyle; IM = Interpersonal manipulation. ${ }^{*} p<.05 ;{ }^{* *} p<.01 ;{ }^{* * *} p<.001$.

As expected, all three men's psychopathy components were negatively related to both women and men's relationship quality. Regarding women's psychopathy components, only ELS was significantly negatively related to both women and men's relationship quality. Profile similarity in psychopathy components was not related to the scores that women and men obtained on these components, and only profile similarity in IM is significantly positively related to women's relationship quality.

In order to explore more thoroughly how similarity in psychopathy components predicts women and men's relationship quality we used polynomial regression analysis and response surface modelling procedures developed by Edwards (2007) 
and Shanock, Baran, Gentry, Pattison, and Heggestad (2010). Before conducting the analyses, the number of couples considered having discrepancies between the two predictors were computed by using procedure suggested by Fleenor, McCauley, and Brutus (1996). Sufficient percentage of discrepant ratings was found $(62.9 \%$ for CT, $65.1 \%$ for ELS, and $69.9 \%$ for IM), that has justified further examination of the effects of the degree and direction of discrepancy in psychopathy components on the relationship satisfaction. Six polynomial regression analyses were performed with each women and men's psychopathy component as predictors and women or men's relationship quality as criterion variables. The regression coefficients thus obtained were used to calculate the response surface parameters a1-a4, which define the response surface plane of a three dimensional plot. We presented only those results of polynomial regression analyses in which significant $R^{2}$ and response surface parameters were obtained.

The results of polynomial regression analysis of ELS on women and men's relationship quality are presented in Table 7 and Figure 2 and 3.

Table 7. Polynomial Regression Analysis of Women and Men's ELS with Women and Men's Relationship Quality

\begin{tabular}{lcc}
\hline & Women's relationship quality & Men's relationship quality \\
& $b(S E)$ & $b(S E)$ \\
\hline Constant & $-0.09(0.15)$ & $-0.14(0.15)$ \\
ELS - W $(b 1)$ & $-0.50(0.30)$ & $-0.73(0.30)^{*}$ \\
ELS - M $(b 2)$ & $-0.25(0.24)$ & $-0.37(0.24)$ \\
ELS - W $(b 3)$ & $-0.32(0.24)$ & $-0.50(0.24)^{*}$ \\
ELS - W x M $(b 4)$ & $0.51(0.30)$ & $0.31(0.29)$ \\
ELS - M M $^{2}(b 5)$ & $-0.47(0.22)^{*}$ & $-0.13(0.23)$ \\
$R^{2}$ & $.17^{* * *}$ & $.17^{* *}$ \\
Congruence line & & $-1.10(0.41)^{* *}$ \\
Slope $(a 1)$ & $-0.75(0.42)$ & $-0.31(0.43)$ \\
Curvature $(a 2)$ & $-0.28(0.43)$ & \\
Incongruence line & & $-0.35(0.35)$ \\
Slope $(a 3)$ & $-0.26(0.36)$ & $-0.94(0.48)$ \\
Curvature $(a 4)$ & $-1.31(0.49)^{* *}$ & \\
\hline
\end{tabular}

Note. $\mathrm{W}$ - women; $\mathrm{M}$ - men; SE - Standard error (reported in parentheses); Polynomial regression coefficients (b1-b5) are unstandardized regression coefficients; ELS = Erratic lifestyle. ${ }^{*} p<.05 ;{ }^{* *} p<.01$.

Regarding women's relationship quality, the results show that the only significant response surface parameter was a4. Its negative sign indicates that a greater disagreement between women and men's ELS is associated with more sharp decrease of women's relationship quality (Figure 2). Considering men's relationship quality, only significant negative a1 parameter was obtained, showing that men's 
relationship quality decreased at the higher levels of women and men's ELS (Figure $3)$.

Figure 2. Women's Relationship Quality as Predicted by Women and Men's ELS. Continuous Line - Line of Congruence. Dotted Line - Line of Incongruence

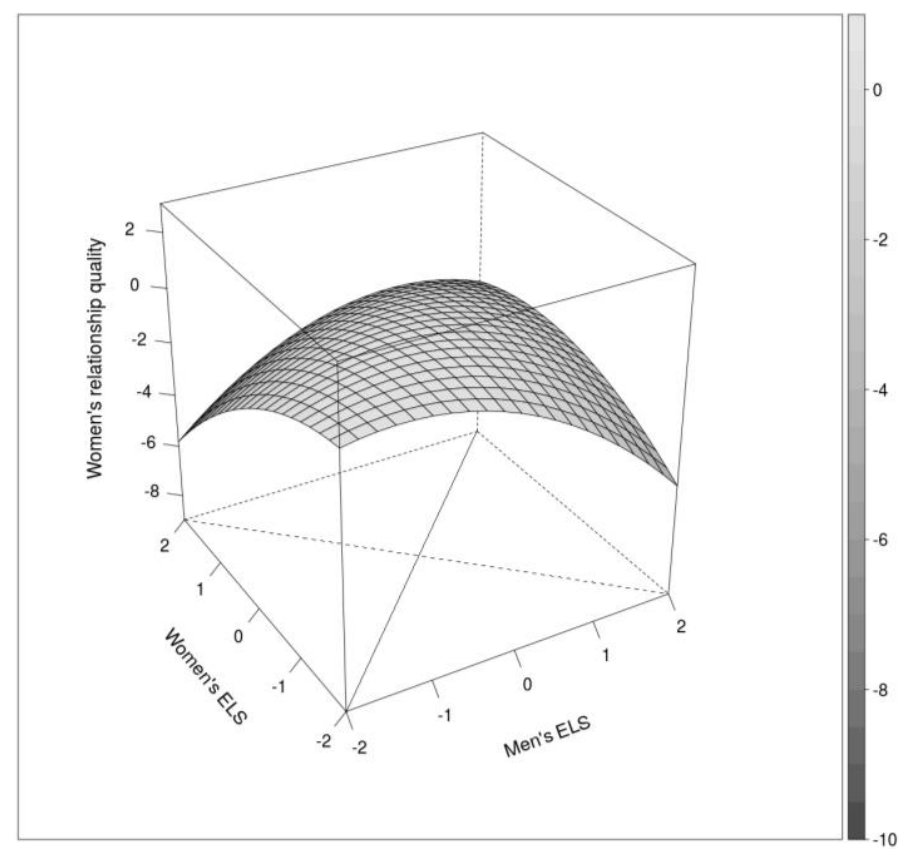


Figure 3. Men's Relationship Quality as Predicted by Women and Men's ELS. Continuous Line - Line of Congruence. Dotted Line - Line of Incongruence

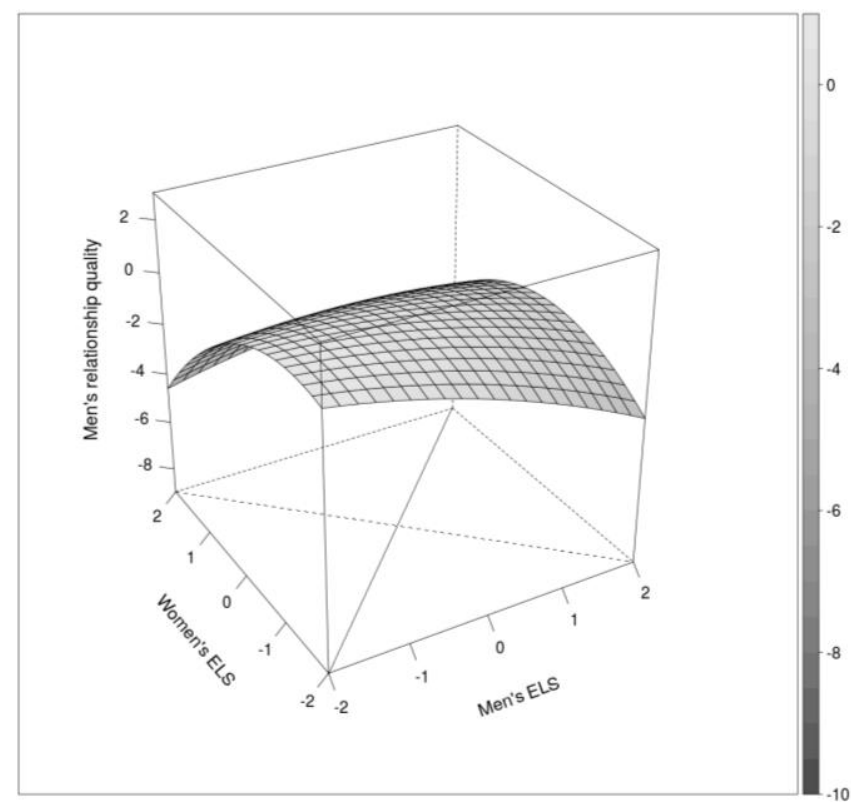

The results of polynomial regression analysis of IM on women and men's relationship quality are presented in Table 8 and Figure 4 and 5.

Table 8. Polynomial Regression Analysis of Women and Men's IM with Women and Men's Relationship Quality

\begin{tabular}{lcc}
\hline & Women's relationship quality & Men's relationship quality \\
& $b(S E)$ & $b(S E)$ \\
\hline Constant & $0.13(0.21)$ & $0.08(0.21)$ \\
$\mathrm{IM}-\mathrm{W}(b 1)$ & $0.44(0.38)$ & $0.66(0.37)$ \\
$\mathrm{IM}-\mathrm{M}(b 2)$ & $-0.79(0.32)^{*}$ & $-0.56(0.31)$ \\
$\mathrm{IM}-\mathrm{W}^{2}(b 3)$ & $-0.02(0.24)$ & $0.13(0.23)$ \\
$\mathrm{IM}-\mathrm{W} \mathrm{x} \mathrm{M}(b 4)$ & $0.38(0.31)$ & $0.43(0.30)$ \\
$\mathrm{IM}-\mathrm{M}^{2}(b 5)$ & $-0.65(0.21)^{* *}$ & $-0.22(0.21)$ \\
$R^{2}$ & $.16^{* *}$ & $.18^{* *}$ \\
\hline Congruence line & & \\
Slope $(a 1)$ & $-0.35(0.47)$ & $0.10(0.46)$ \\
Curvature $(a 2)$ & $-0.30(0.36)$ & $0.34(0.46)$ \\
Incongruence line & & $1.21(0.51)^{*}$ \\
Slope $(a 3)$ & $1.23(0.52)^{*}$ & $-0.53(0.32)$ \\
Curvature $(a 4)$ & $-1.06(0.45)^{*}$ & \\
\hline
\end{tabular}

Note. $\mathrm{W}$ - women; $\mathrm{M}$ - men; SE - Standard error (reported in parentheses); Polynomial regression coefficients (b1-b5) are unstandardized regression coefficients; IM = Interpersonal manipulation. ${ }^{*} p<.05 ;{ }^{* *} p<.01$. 
Regarding women's relationship quality, significant positive a3 and negative a4 response surface parameters were obtained. Therefore, a greater disagreement between women and men's IM resulted in a lower women's relationship quality. However, women's relationship quality was higher when women's IM was higher than men's (Figure 4). When men's relationship quality was taken into account, significant positive a3 parameter was obtained, showing that men's relationship quality was higher when women's IM was higher than men's (Figure 5).

Figure 4. Women's Relationship Quality as Predicted by Women and Men's IM. Continuous Line - Line of Congruence. Dotted Line - Line of Incongruence

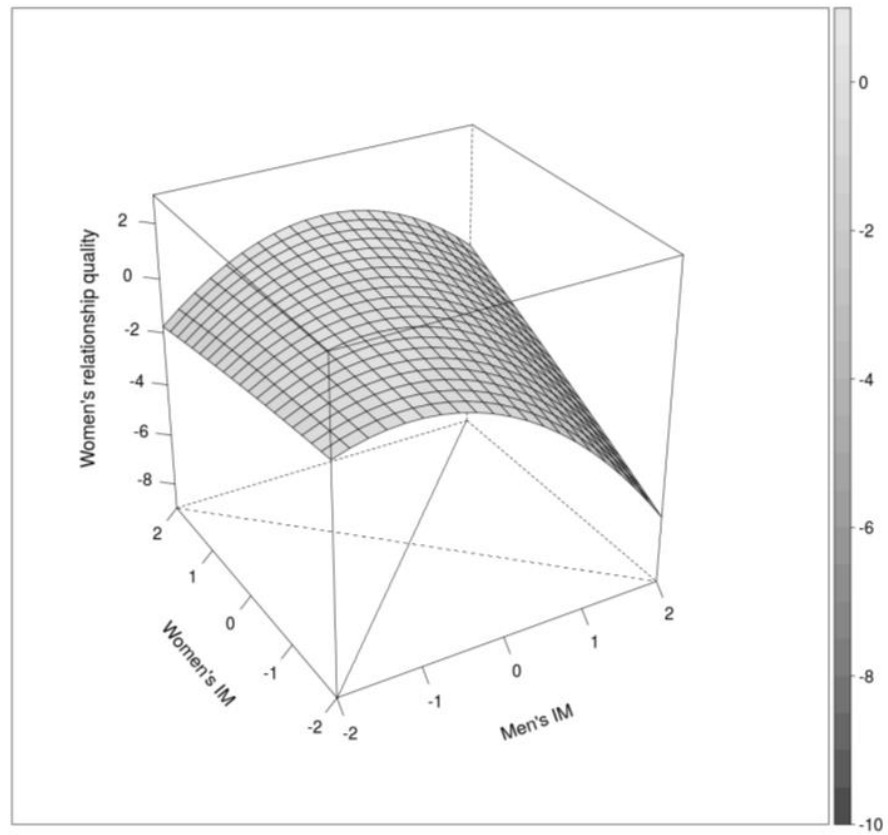


Figure 5. Men's relationship quality as predicted by women and men's IM. Continuous Line - Line of Congruence. Dotted Line - Line of Incongruence

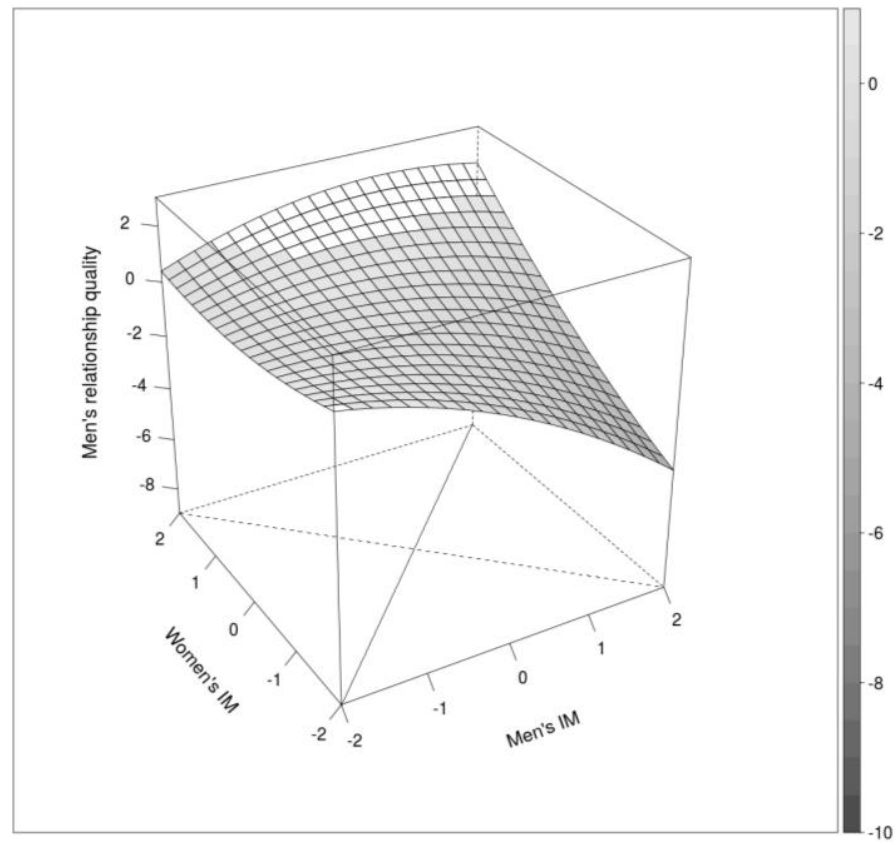

\section{Discussion}

The results concerning the structure of SRP-III-E questionnaire in Croatian language show that three-factor structure is the most adequate. Compared to the previous studies (Neumann et al., 2012; Williams et al., 2007) this study confirmed CT, ELS and IM factors, while CA factor was not replicated because of its very low reliability. Therefore, three factors were used in subsequent studies. The assortment between intimate partners in psychopathy as a latent construct estimated by structural modelling was moderate (.44) (Figure 1) and somewhat greater than the assortment usually obtained for other personality traits as well as psychopathy (Kardum et al., 2016; Savard et al., 2011).

When it comes to the specific components of psychopathy, significant positive assortment for CT was found by using VCA, but not by using CCA because the level of assortment was the same as the one obtained for random couples. Both approaches dominantly confirmed initial assortment rather than convergence hypothesis and active assortment rather than social homogamy hypothesis, although CCA suggests a slight tendency towards divergence and social homogamy. Namely, relationship duration and sociodemographic variables were not related to the initial similarity in CT level (VCA) (Table 4), but couples with shorter relationship duration as well as 
couples with younger women had somewhat higher profile similarity (CCA). Interestingly, mean profile similarity obtained for CT was very high (.60), higher than for ELS (.35) and IM (.37), but CCA still suggested the absence of positive assortment because of very high mean profile similarity obtained for random couples (.55). This could be explained by high stability of the rank order of criminal behaviors described by CT items in subclinical population. Namely, some more serious criminal behaviors (e.g. "Broken into a building or vehicle to steal or vandalize") are probably in majority of subclinical population very rare, while the milder ones (e.g. "Avoided paying for things") are more frequent. Thus, higher stability in the rank order of the criminal behaviors led to the high profile similarity even in random couples. Weak tendencies towards divergence and social homogamy in CT obtained only by CCA may have been the result of greater attractiveness of the similarity in $\mathrm{CT}$ at the early stages of the relationship and may have reflected the initial choice of mates from similar social environments. It should be emphasized that it is not possible to separate the effects of relationship duration and age on profile similarity in a cross-sectional study, and especially having in mind developmental changes in criminal behaviors (Blonigen, Hicks, Krueger, Patrick, \& Iacono, 2006).

ELS is the only component of psychopathy in which positive assortment was found by both VCA and CCA. Furthermore, both approaches predominantly confirmed the hypotheses of initial and active assortment. Only by using CCA, we observed a slight tendency toward social homogamy, i.e. the similarity between profiles was greater for those couples in which the man was more educated compared to the couples in which the man was less educated. This may suggest that similarity between partners in ELS is partly a consequence of similar socioeconomic status (SES). Although women and men's education were not related to ELS (Table 3), education is the only one of several SES indicators (e.g. income, occupation, wealth) that could be related to ELS.

Assortment for IM was not obtained when VCA was used, but CCA showed that the assortment for this psychopathy component was higher than for the other two. In other words, partners were not similar in the levels of IM, but the content of their IM was congruent, i.e. they manifested similar instances of IM. Along with somewhat lower reliability of IM scale, these results may indicate that the content of IM rather than its levels is relevant in initial partner selection. The results obtained by CCA mainly confirmed the hypotheses of initial and active assortment, with a slight tendency towards divergence. Namely, the greater was relationship duration the lesser was the similarity between partners' profiles in IM. This result is similar to the one obtained for CT and may also suggest that profile similarity in IM is more attractive to partners at an earlier stage of the relationship.

To summarize, positive assortment for all three components of psychopathy has been found either by using only VCA (CT), only CCA (IM) or both approaches (ELS). Our results suggest that similarity in personality traits, even when socially undesirable, may lead to the initial attraction, empathy and mutual understanding 
between partners, which may further promote better relationship development and satisfaction over time. Furthermore, initial assortment rather than convergence hypothesis and active assortment rather than social homogamy hypothesis were confirmed to a great degree for all three psychopathy components. Tendency towards divergence found for CT and IM suggests that for socially problematic traits gradual dissimilarity between partners over time may have contributed to the relationship maintenance, compared to some socially desirable traits (e.g. agreeableness, conscientiousness and openness), for which convergence was found to be beneficial (Rammstedt \& Schupp, 2008).

The assortment for three psychopathy components found in this study may have some additional consequences. One of them relates to human genetics because reproduction of partners similar in psychopathy components may increase genetic variability and heritability by increasing additive genetic variance. Even if assortment is of a modest degree, it can contribute to the great increase of genetic variability by accumulating its effects over generations (Plomin et al., 2013). Thus, our results about positive assortment of different components of psychopathy suggest that in future studies similarity between partners should be modeled in order to estimate accurately heritability of its components. Furthermore, homogeneous family environments created by similar parents may have important impact on the socialization of children's psychopathic tendencies.

Polynomial regression analyses show that (dis)similarity in ELS and IM exerted significant effects both on women and men's relationship quality, while (dis)similarity in CT did not exert any significant effects. The results regarding CT may be the consequence of men's, and especially women's low scores and low variability on this scale.

Greater disagreement between women and men's ELS was associated with more sharp decrease of women's relationship quality (Figure 2), while men's relationship quality decreased at the higher levels of women and men's ELS (Figure 3). We can assume that living with a partner who has different life-style and different level of sensation seeking can lead to the problems in communication, understanding and organization of daily activities, which may be detrimental to the relationship quality especially for women who are more sensitive to these aspects. On the other hand, lower men's relationship quality at higher levels of women and men's ELS may be the consequence of men's gender role, which prescribes their dominance, and, when not fulfilled, may provoke conflicts between partners.

Greater disagreement between women and men's IM resulted in lower women's relationship quality. On the other hand, profile similarity in IM was significantly positively related to women's relationship quality. These results once again show that disagreement had negative, while agreement positive effects on women's relationship quality, even when socially problematic traits, such as IM were considered. They also show that women were more sensitive than men were to the effects of (dis)similarities in personality traits. Interestingly, when there was a disagreement, 
both women and men's relationship quality were higher when women's IM was higher than men's (Figure 4 and 5). Women who showed greater IM than their partners had probably higher sense of proactivity, efficacy and control, and, at the same time, men whose partners showed higher manipulation may have perceived them as more committed to the relationship and also more resourceful. Dynamic nature of intimate relations between partners and their relationship quality may have been also involved, because relationship quality in one partner contributes to the relationship quality in other.

The results obtained should be considered having in mind several limitations of this study, such as cross-sectional design and the use of self-report measure. The latter is especially important because psychopaths frequently lie and may lack insight into the nature and extent of their psychological characteristics. For example, because of their reduced experience of certain affective states such as guilt and empathy, they may not be able to accurately estimate them (Lilienfeld \& Fowler, 2006). Furthermore, we used the experimental version of psychopathy scale that was previously not extensively used, although some studies showed its high correlation with the most recent and more comprehensive measure of psychopathy, SRP III (Neal \& Selbom, 2012; Paulhus et al., in press). The use of SRP-III-E probably disabled the identification of callous affect factor, an important component of psychopathy that is not included in this study. Future studies should take into account aforementioned limitations and, following the results of this study, should focus more towards better understanding of the nature and consequences of specific psychopathy components rather than psychopathy as a unitary construct.

\section{References}

Ali, F., \& Chamorro-Premuzic, T. (2010). The dark side of love and life satisfaction: Associations with intimate relationships, psychopathy and Machiavellianism. Personality and Individual Differences, 48(2), 228-233. doi: 10.1016/j.paid.2009. 10.016

Andrade, J.T. (2008). The inclusion of antisocial behavior in the construct of psychopathy. A review of the research. Aggression and Violent Behavior, 13(4), 328-335. doi: 10.1016/j.avb.2008.05.001

Baughman, H.M., Jonason, P.K., Lyons, M., \& Vernon, P.A. (2014). Liar liar pants on fire: Cheater strategies linked to the Dark Triad. Personality and Individual Differences, 71, 35-38. doi: 10.1016/j.paid.2014.07.019

Blonigen, D.M., Hicks, B.M., Krueger, R.F., Patrick, C.J., \& Iacono, W.G. (2006). Continuity and change in psychopathic traits as measured via normal-range personality: A longitudinal-biometric study. Journal of Abnormal Psychology, 115(1), 85-95. doi: 10.1037/0021-843x.115.1.85

Buss, D.M. (1984). Marital assortment for personality dispositions: Assessment with three different data sources. Behavior Genetics, 14, 111-123. doi: 10.1007/BF01076408 
Cleckley, H. (1941). The mask of sanity. St. Louis, MO: C.V. Mosby.

Cooke, D.J., \& Michie, C. (2001). Refining the construct of psychopathy: Towards a hierarchical model. Psychological Assessment, 13(2), 171-188. doi: 10.1037/10403590.13.2.171

Ćubela Adorić, V., \& Vugdelija, P. (2010). Skala bračne stabilnosti. In I. Tucak Junaković, V. Ćubela Adorić, A. Proroković, \& Z. Penezić (Eds.), Zbirka psihologijskih skala i upitnika (Vol. 5, pp. 17-22). Zadar: University of Zadar.

Dubuis-Stadelmann, E., Fenton, B.T., Ferrero, F., \& Preisig, M. (2001). Spousal similarity for temperament, personality, and psychiatric symptomology. Personality and Individual Differences, 30(7), 1095-1112. doi: 10.1016/s0191-8869(00)00092-1

Edwards, J.R. (2007). Polynomial regression response surface methodology. In C. Ostroff \& T.A. Judge (Eds.), Perspectives on organizational fit (pp. 361-372). San Francisco: Jossey-Bass.

Figueredo, A.J., Vásquez, G., Brumbach, B.H., Schneider, S.M.R., Sefcek, J.A., Tal, I.R., Hill, D., Wenner, C.J., \& Jacobs, J. (2006). Consilience and Life History Theory: From genes to brain to reproductive strategy. Developmental Review, 26(2), 243-275. doi: 10.1016/j.dr.2006.02.002

Fleenor, J.W., McCauley, C.D., \& Brutus, S. (1996). Self-other rating agreement and leader effectiveness. Leadership Quarterly, 7(4), 487-506. doi: 10.1016/s1048-9843(96) 90003-x

Fletcher, G.J.O., Simpson, J.A., \& Thomas, G. (2000). The measurement of perceived relationship quality components: A confirmatory factor analytic approach. Personality and Social Psychology Bulletin, 26(3), 340-354. doi: 10.1177/0146167200265007

Furnham, A., Richards, S.C., \& Paulhus, D.L. (2013). The Dark Triad of personality: A 10 year review. Social and Personality Psychology Compass, 7(3), 199-216. doi: 10. $1111 /$ spc3.12018

Gladden, P.R., Sisco, M., \& Figueredo, A.J. (2008). Sexual coercion and life-history strategy. Evolution and Human Behavior, 29(5), 319-326. doi: 10.1016/j.evolhumbehav.2008. 03.003

Glenn, A.L., \& Raine, A. (2014). Psychopathy: An introduction to biological findings and their implications. New York and London: New York University Press.

Hare, R.D. (1980). A research scale for the assessment of psychopathy in criminal populations. Personality and Individual Differences, 1(2), 111-117. doi: 10.1016/ 01918869(80)90028-8

Hare, R.D. (1985). Comparison of procedures for the assessment of psychopathy. Journal of Consulting and Clinical Psychology, 53(1), 7-16. doi: 10.1037//0022-006x.53.1.7

Hare, R.D. (1991). The Hare Psychopathy Checklist-Revised (PCL-R). Toronto, ON: MultiHealth Systems.

Hare, R.D. (2003). Manual for the Revised Psychopathy Checklist, 2nd ed. Toronto, ON: Multi-Health Systems. 
Hare, R.D., Harpur, T.J., \& Hemphill, J.D. (1989). Scoring pamphlet for the Self-Report Psychopathy scale: SRP-II. Unpublished manuscript. Simon Fraser University, Vancouver, British Columbia, Canada.

Hare, R.D., \& Neumann, C.S. (2006). The PCL-R assessment of psychopathy: Development, structural properties, and new directions. In C.J. Patrick (Ed.), Handbook of psychopathy (pp. 58-88). New York: Guilford.

Hu, L.T., \& Bentler, P.M. (1998). Fit indices in covariance structure modeling: Sensitivity to underparameterized model misspecification. Psychological Methods, 3, 424-53. doi: 10.1037/1082-989X.3.4.424

Jonason, P.K., Koenig, B.L., \& Tost, J. (2010a). Living a fast life: The Dark Triad and Life History Theory. Human Nature, 21(4), 428-442. doi: 10.1007/s12110-010-9102-4

Jonason, P.K., Li, N.P., \& Buss, D.M. (2010b). The costs and benefits of the Dark Triad: Implications for mate poaching and mate retention tactics. Personality and Individual Differences, 48(4), 373-378. doi: 10.1016/j.paid.2009.11.003

Jones, D.N., \& Paulhus, D.L. (2010). Differentiating the Dark Triad within the interpersonal circumplex. In L.M. Horowitz \& S. Strack (Eds.), Handbook of interpersonal psychology: Theory, research, assessment, and therapeutic interventions (pp. 249-269). New York: Wiley \& Sons.

Jones, D.N., \& Weiser, D.A. (2014). Differential infidelity patterns among the Dark Triad. Personality and Individual Differences, 57, 20-24. doi: 10.1016/j.paid.2013.09.007

Jöreskog, K.G., \& Sörbom, D. (1999). LISREL 8 user's reference guide. Lincolnwood, IL: Scientific Software International.

Kardum, I., Hudek-Knezevic, J., Schmitt, D., \& Covic, M. (2016). Assortative mating for Dark triad traits: Evidence of positive, initial, and active assortment. Personal Relationships, 24(1), 75-83. doi: 10.1111/pere.12168

Kardum, I., Hudek-Knezevic, J., Schmitt, D.P., \& Grundler, P. (2015). Personality and mate poaching experiences. Personality and Individual Differences, 75, 7-12. doi: 10.1016/ j.paid.2014.10.048

Kline, R.B. (1998). Principles and practice of structural equation modeling. New York: The Guilford Press.

Krueger, R.F., Moffit, T.E., Caspi, A., Bleske, A., \& Silva, P.A. (1998). Assortative mating for antisocial behavior: Developmental and methodological implications. Behavior Genetics, 28(3), 173-186. doi: 10.1023/A:1021419013124

Lee, K., \& Ashton, M.C. (2005). Psychopathy, Machiavellianism, and narcissism in the FiveFactor Model and the HEXACO model of personality structure. Personality and Individual Differences, 38(7), 1571-1582. doi: 10.1016/j.paid.2004.09.016

Lilienfeld, S.O., \& Fowler, K.A. (2006). The self-report assessment of psychopathy. In C. J. Patrick (Ed.), Handbook of psychopathy (pp. 107-132). New York: The Guilford Press.

Lilienfeld, S.O., \& Widows, M.R. (2005). Professional manual for the Psychopathic Personality Inventory-Revised: (PPI-R). Lutz, FL: Psychological Assessment Resources. 
Low, N., Cui, L., \& Merikangas, K.R. (2007). Spousal concordance for substance use and anxiety disorders. Journal of Psychiatric Research, 41(11), 942-951. doi: 10.1016/ j.jpsychires.2006.11.003

Luo, S., \& Klohnen, C. (2005). Assortative mating and marital quality in newlyweds: A couple-centered approach. Journal of Personality and Social Psychology, 88(2), 304326. doi: 10.1037/0022-3514.88.2.304

Mahmut, M., Menictas, C., Stevenson, R.J., \& Homewood, J. (2011). Validating the factor structure of the Self-Report Psychopathy (SRP) in a community sample. Psychological Assessment, 23(3), 670-678. doi: 10.1037/a0023090

Mathews, C.A., \& Reus, V.I. (2001). Assortative mating in the affective disorders: A systematic review and meta-analysis. Comprehensive Psychiatry, 42(4), 257-262. doi: 10.1053/comp.2001.24575

McCrae, R.R., Martin, T.A., Hrebícková, M., Urbánek, T., Boomsma, D.I., Willemsen, G., \& Costa, P.T. (2008). Personality trait similarity between spouses in four cultures. Journal of Personality, 76(5), 1137-1164. doi: 10.1111/j.1467-6494.2008.00517.x

Neal, T.M.S., \& Selbom, M. (2012). Examining the factor structure of the Hare Self-Report Psychopathy (SRP) Scale. Journal of Personality Assessment, 94(3), 244-253. doi: 10.1080/00223891.2011.648294

Neumann, C.S., \& Hare, R.D. (2008). Psychopathic traits in a large community sample: Links to violence, alcohol use, and intelligence. Journal of Consulting and Clinical Psychology, 76(5), 893-899. doi: 10.1037/0022-006x.76.5.893

Neumann, C.S., Schmitt, D.S., Carter, R., Embley, I., \& Hare, R.D. (2012). Psychopathic traits in females and males across the globe. Behavioral Sciences \& the Law, 30(5), 557 574. doi: $10.1002 / \mathrm{bsl} .2038$

Neumann, C.S., Vitacco, M.J., Hare, R.D., \& Wupperman, P. (2005). Re-construing the "Reconstruction" of psychopathy: A comment on Cooke, Michie, Hart \& Clarke. Journal of Personality Disorders, 19(6), 624-640. doi: 10.1521/pedi.2005.19.6.624

O'Boyle, E., Forsyth, D.R., Story, P.A., \& White, C.D. (2014). A Meta-analytic test of redundancy and relative importance of the Dark Triad and Five-Factor Model of personality. Journal of Personality, 83(6), 644-664. doi: 10.1111/jopy.12126

Paulhus, D.L., Neumann, C.S., \& Hare, R.D. (in press). Manual for the Hare Self-Report psychopathy scale. Toronto: Multi-Health Systems.

Paulhus, D.L., \& Williams, K.M. (2002). The Dark Triad of personality: Narcissism, Machiavellianism, and psychopathy. Journal of Research in Personality, 36(6), 556563. doi:10.1016/S0092-6566(02)00505-6

Pérez, B., Herrero, J., Velasco, J., \& Javier Rodriguez-Díaz, F. (2015). A contrastive analysis of the factorial structure of the PCL-R: Which model fits best the data? The European Journal of Psychology Applied to Legal Context, 7(1), 23-30. doi: 10.1016/ j.ejpal.2014.10.001

Plomin, R., DeFries, J.C., Knopik, V.S., \& Neiderhiser, J. (2013). Behavioral genetics (6th ed.). New York: Worth Publishers. 
Rammstedt, B., \& Schupp, J. (2008). Only the congruent survive - Personality similarity in couples. Personality and Individual Differences, 45(6), 533-535. doi: 10.1016/ j.paid. 2008.06.007

Rasmussen, K.R., \& Boon, S.D. (2014). Romantic revenge and the Dark Triad: A model of impellance and inhibition. Personality and Individual Differences, 56, 51-56. doi: 10.1016/j.paid.2013.08.018

Savard, C., Sabourin, S., \& Lussier, Y. (2011). Correlates of psychopathic personality traits in community couples. Personality and Mental Health, 5(3), 186-199. doi: 10.1002/ pmh.159

Schermelleh-Engel, K., Moosbrugger, H., \& Müller, H. (2003). Evaluating the fit of structural equation models: Tests of significance and descriptive goodness-of-fit measures. Methods of Psychological Research Online, 8(2), 23-74.

Schmitt, D.P. (2002). Personality, attachment and sexuality related to dating relationship outcomes: Contrasting three perspectives on personal attribute interaction. British Journal of Social Psychology, 41(4), 589-610. doi: 10.1348/014466602321149894

Shackelford, T.K., Goetz, A.T., \& Buss, D.M. (2005). Mate retention in marriage: Further evidence of the reliability of the Mate Retention Inventory. Personality and Individual Differences, 39(2), 415-425. doi: 10.1016/j.paid.2005.01.018

Shanock, L.R., Baran, B.E., Gentry, W.A., Pattison, S.C., \& Heggestad, E.D. (2010). Polynomial regression with response surface analysis: A powerful approach for examining moderation and overcoming limitations of difference scores. Journal of Business and Psychology, 25(4), 543-554. doi: 10.1007/s10869-010-9183-4

Simpson, J.A. (1987). The dissolution of romantic relationships: Factors involved in relationship stability and emotional distress. Journal of Personality and Social Psychology, 53(4), 683-692. doi: 10.1037/0022-3514.53.4.683

Smith, V.C., Hadden, B.W., Webster, G.D., Jonason, P.K., Gesselman, A.N., \& Crysel, L.C. (2014). Mutually attracted or repulsed? Actor-partner interdependence models of Dark Triad traits and relationship outcomes. Personality and Individual Differences, 67, 3541. doi: 10.1016/j.paid.2014.01.044

Thiessen, D., \& Gregg, B. (1980). Human assortative mating and genetic equilibrium: An evolutionary perspective. Ethology and Sociobiology, 1(2), 111-140. doi: 10.1016/ 0162-3095(80)90003-5

Vitacco, M.J., Neumann, C.S., \& Jackson, R.L. (2005). Testing a four-factor model of psychopathy and its association with ethnicity, gender, intelligence, and violence. Journal of Consulting and Clinical Psychology, 73(3), 466-476. doi: 10.1037/0022006x.73.3.466

Watson, D., Klohnen, E.C., Casillas, A., Nus Sims, E., Haig, J., \& Berry, D.S. (2004). Match makers and deal breakers: Analyses of assortative mating in newlywed couples. Journal of Personality, 72(5), 1029-1068. doi: 10.1111/j.0022-3506.2004.00289.x

Williams, K.M., Nathanson, C., \& Paulhus, D.L. (2003, August). Structure and validity of the Self-Report Psychopathy scale-III in normal populations. Poster session presented the meeting of the American Psychological Association, Toronto, Canada. 
Williams, K.M., Paulhus, D.L., \& Hare, R.D. (2007). Capturing the four-factor structure of psychopathy in college students via self-report. Journal of Personality Assessment, 88(2), 205-219. doi: 10.1080/00223890701268074

\section{Emparejamiento selectivo para los componentes de psicopatía y sus efectos sobre la calidad de la relación en parejas íntimas}

\section{Resumen}

En tres estudios hemos examinado emparejamiento selectivo para los componentes de psicopatía, tanto como sus efectos sobre la calidad de la relación en parejas íntimas. Comparado con la estructura original, hemos confirmado tres factores de psicopatía: tendencias criminales (TC), estilo de vida errático (EVE) y manipulación interpersonal (MI), mientras que afecto cruel no se ha manifestado. Se han examinado hipótesis sobre surtido positivo contra negativo, emparejamiento inicial contra convergencia y emparejamiento activo contra homogamia social. Todas las hipótesis se han investigado a través del enfoque centrado en la variable (ECV) y el enfoque centrado en la pareja (ECP). Hemos encontrado un surtido moderadamente positivo entre parejas íntimas en la psicopatía como constructo latente valuado por el modelado estructural. Además, surtido positivo para todas las tres componentes de psicopatía se ha encontrado sea sólo a través del ECV (TC), sólo ECP o los dos enfoques (EVE). Además, para todos los tres componentes de psicopatía se ha confirmado el surtido inicial en lugar de la hipótesis de la convergencia y el surtido activo en lugar de la hipótesis de la homogamia social, con la tendencia ligera hacia la divergencia y la homogamia social. Hemos examinado los efectos de la similitud en los componentes de psicopatía en la calidad de relación de hombre y mujeres usando la similitud de perfil y análisis regresivo polinomio. La similitud de perfil en MI estaba significativa y positivamente relacionada con la calidad de la relación de mujeres, mientras que los resultados del análisis regresivo polinomio era más complejos y demostraron que sólo la (di)similitud en TC no ejerció ningún efecto sobre la calidad de relación de hombre y mujeres. Una mayor discrepancia entre el EVE de hombres y mujeres fue relacionada con una disminución marcada de la calidad de la relación de mujeres, mientras que la calidad de la relación de hombres disminuyó a niveles más altos del EVE de mujeres y hombres. Una mayor discrepancia entre la MI de mujeres y hombres resulta con la calidad más baja de la relación de mujeres, mientras que la calidad de la relación de mujeres y hombres fue más alta cuando la MI de mujeres fue más alta que la de los hombres.

Palabras claves: componentes de psicopatía, emparejamiento selectivo, surtido inicial, surtido activo, calidad de la relación 